\title{
Double-blind trial of the use of transfer factor in the treatment of Crohn's disease ${ }^{1}$
}

\author{
F. R. VICARY', J. D. CHAMBERS, AND P. DHILLON \\ From the Departments of Gastroenterology and Chemical Pathology, Westminster Hospital, London
}

SUMMARY We have undertaken a double-blind controlled trial of the use of transfer factor in Crohn's disease. Thirty-three patients with known Crohn's disease completed the trial in which half the patients had three injections of transfer factor and the other half were given saline. After six months there was no significant difference in the clinical condition of either of the two groups compared with before receiving treatment. There was also no difference in their in vitro lymphocyte function, although a number of patients exhibited altered responsiveness to skin testing with tuberculin or streptokinase/streptodornase. A significant fall on Crohn's disease activity index score occurred over the initial 'acclimatising period' before the trial was started, probably related to overcoming initial introspection and the placebo effect of being part of a trial.

The controversy over anergy in Crohn's disease remains unsolved. Numerous papers have suggested either the presence of a degree of anergy (Asquith et al., 1973; Meuwissen et al., 1975; Meyers et al., 1976) or complete normality of response. (Binder et al., 1966; Bird and Britton 1974; Bolton et al., 1974).

The ability to modulate T-lymphocyte function and 'transfer' immunological information has been known for some time (Lawrence, 1955). The medium whereby information is transferred is known as 'transfer factor' in the absence of definite knowledge of its molecular structure. Transfer factor has been shown to be capable of stimulating lymphocyte function both in vivo by conversion of skin tests and in vitro (Lawrence, 1970). In diseases where there is a specific defect of $T$ cell function-for example, mucocutaneous candidiasis-transfer factor therapy has produced marked clinical improvement (Pabst and Swanson, 1972; Graybill et al., 1973; Rocklin, 1975). In some viral diseases there has also been clinical improvement after therapy (O'Connell et al., 1964). In many diseases, especially those in which there are non-specific $T$ cell abnormalities, transfer factor has been disappointing (Lawrence, 1969).

Asquith et al., (1975) in a preliminary study showed

${ }^{1}$ This work was supported by Medical Research Council Grant No. G976/527.

'Present address: Royal Northern Hospital, Holloway Road, London N16.

Received for publication 20 November 1978 the possibility of effective treatment of Crohn's disease using transfer factor. Their paper showed some improvement in the patient's condition with transfer factor therapy, but the trial was not a controlled study. It was decided, therefore, to conduct a double-blind controlled trial of transfer factor on Crohn's disease.

\section{Methods}

Forty patients with Crohn's disease attending the Westminster Hospital were selected for the trial. All patients fulfilled the clinical criteria of Crohn's disease as used by Lennard-Jones et al. (1976).

Thirty-four patients had unequivocally positive histology of Crohn's disease with tuberculoid granulomas in biopsy specimens or surgically resected bowel. In six patients, histology was not available but all had unequivocal clinical and radiological features of the disease.

The patients were assessed initially as to the anatomical site of their disease and divided into three groups accordingly. Group 1 had only small bowel disease, group 2 had ileal and colonic disease, often in continuity, and group 3 had only colonic disease. These patients were then divided between the placebo and transfer factor groups to provide approximately equal numbers in each group. (Table 1).

By the end of the trial 33 patients remained. One patient changed his mind and dropped out before 408 
Table 1 Comparison of disease extent in two groups at start of trial

\begin{tabular}{llll}
\hline Group & Disease & & \\
\cline { 2 - 4 } & Small bowel only & $\begin{array}{l}\text { lleal and } \\
\text { colonic }\end{array}$ & $\begin{array}{l}\text { Colonic } \\
\text { only }\end{array}$ \\
\hline Transfer factor & 4 & 7 & 4 \\
Placebo & 3 & 9 & 6
\end{tabular}

receiving any treatment. One patient felt unwell after the first injection and refused to continue. One patient died of carcinoma of the bronchus during the course of the trial. This tumour was not suspected when she was included in the trial but became apparent after the second visit: she was dead one month after the diagnosis was made. Four patients (all in the transfer factor group) required major surgical procedures during the trial and were removed from the final analysis.

The trial was explained in detail beforehand to all patients.

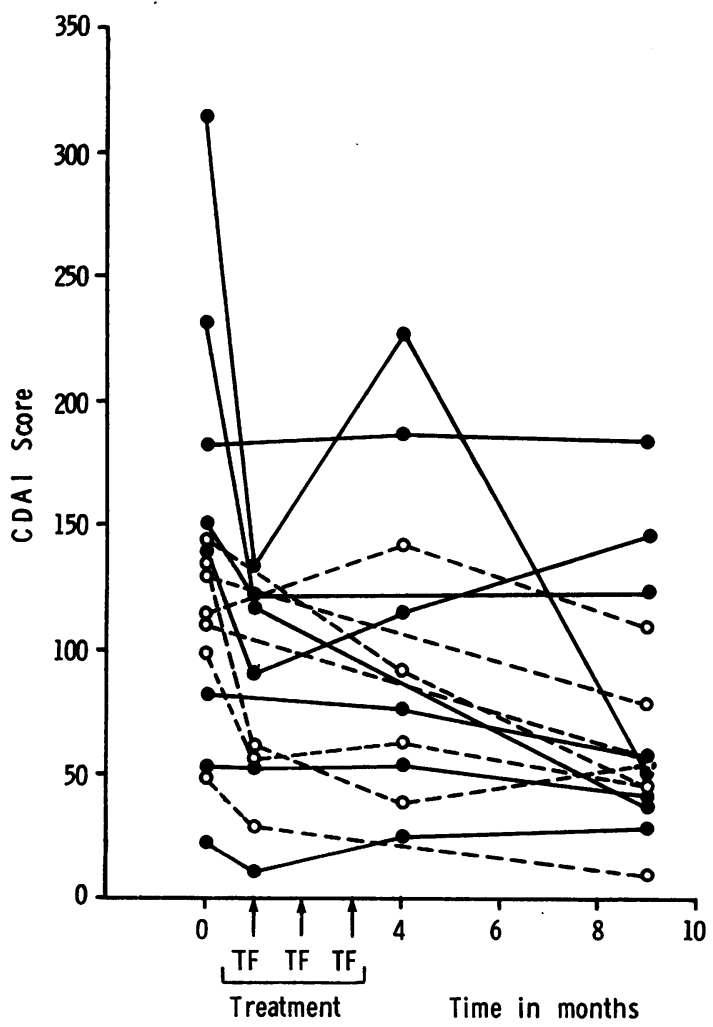

Fig. 1 Effect of transfer factor on CDAI score. Skin tests: changed $\mathrm{O}_{-}---\mathrm{O}$, unchanged $-\longrightarrow$
CLINICAL ASSESSMENT

The assessment of activity of the disease was made using the Crohn's Disease Activity Index (CDAI) of Best et al. (1976).

The patients were each given a diary card on which they assessed for seven days before their outpatient visit; the number of loose stools, the level of abdominal pain, and their general well-being. Using a combination of clinical and haematological parameters, a final score (CDAI) was obtained. In evaluating their system, Best et al. decided that a score above 150 indicated active disease and below 150 indicated quiescent disease. These figures apply to groups and not to individual patients For instance, an individual patient could have abdominal pain and a discharging fistula. This patient obviously has clinically active disease but could have a CDAI score well below 150 .

The CDAI was measured on the first visit, one month later, and then one month and six months after treatment or placebo (Table 2).

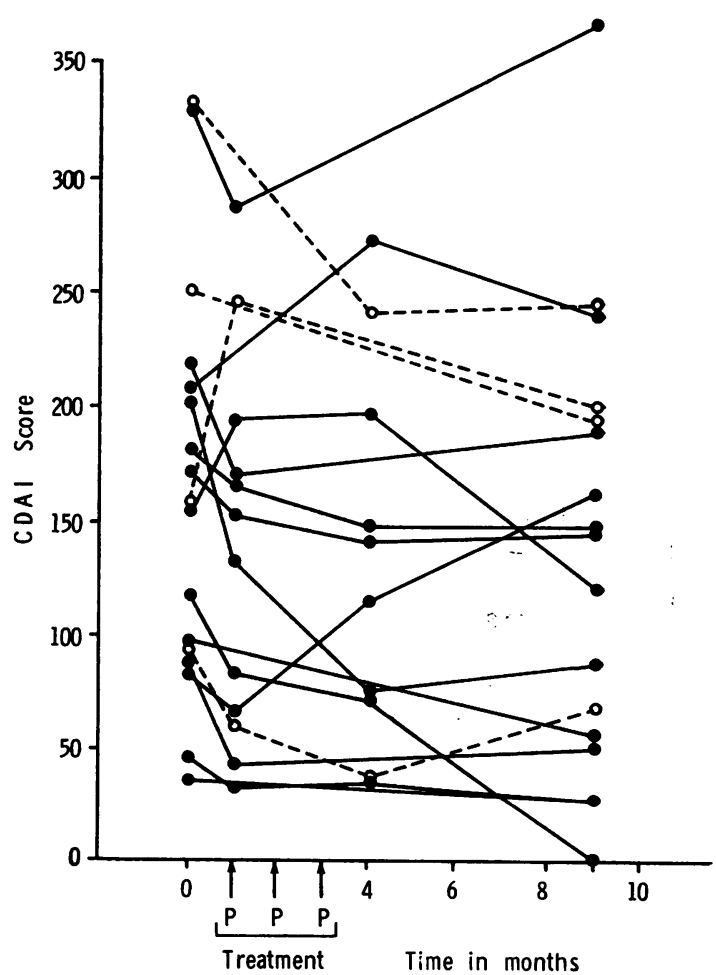

Fig. 2 Effect of placebo on CDAI score. Skin tests: changed $\mathrm{O}-\mathrm{O}_{-} \mathrm{O}$, unchanged $-\mathrm{O}$ 
Table 2 Timetable of each patient's progress in trial

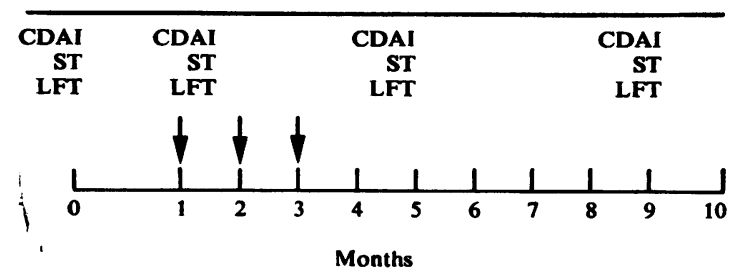

CDAI : Crohn's Disease Activity Index

ST : Skin tests

LFT : Lymphocyte function tests

$\downarrow$ : Injection of transfer factor or placebo

\section{SKIN TESTS}

One hundred units of Old Tuberculin (Ministry of Agriculture, Fisheries \& Food, Weybridge) were injected intradermally on the volar surface of the forearm; 125 units of streptokinase/streptodornase (SK/SD Lederle) was also injected intradermally. A negative result was considered to be less than $10 \mathrm{~mm}$ induration when read $\mathbf{4 8}$ hours later.

\section{In vitro LYMPHOCYTE STUDIES}

Twenty-five millilitres of venous blood was taken into a tube containing $500 \mathrm{IU}$ of preservative-free sodium heparin. Plasma was removed and, after reconstitution to $25 \mathrm{ml}$ with TC 199 medium (Wellcome), lymphocytes were separated using Lymphoprep (Nyegaard, Oslo), washed three times with TC 199, and finally resuspended to $2 \times 10^{6}$ per $\mathrm{ml}$.

$T$ cells were enumerated using the $E$ rosette test. Approximately $3 \times 10^{6}$ lymphocytes were used, with a $1 \%$ suspension of sheep red cells in $25 \%$ foetal calf serum (FCS) or TC 199. Incubation times were 15 minutes at $37^{\circ} \mathrm{C}$ then $4^{\circ} \mathrm{C}$ overnight. The same batch of serum was used throughout.

B cells were enumerated using fluorescein conjugated antihuman immunoglobulin (Wellcome MF 01) in excess and counting was performed on a Leitz UV microscope.

Cultures were set up in quadruplicate in flat-welled microtitre plates (Sterilin M2AR) using $10^{5}$ responding cells per well in $25 \%$ autologous plasma or heat inactivated pooled AB sera. Stimulants used were phytohaemagglutinin, $2.5 \mu \mathrm{g} / \mathrm{ml}$ (Wellcome HA 16), candida immunogen, $25 \mu \mathrm{g} / \mathrm{ml}$ (lyophilised whole extract, NIBSC), tuberculin PPD $10 \mu \mathrm{g} / \mathrm{ml}$ (PPD 298, MAFF, Weybridge) or $10^{5}$ mitomycinblocked lymphocytes from a pool of five random subjects. Final volume of cultures was $0.2 \mathrm{ml}$.

Plates were sealed with sterile self-adhesive gas permeable plastic film and incubated at $37^{\circ} \mathrm{C}$ in an atmosphere containing $5 \% \mathrm{CO}_{2}$. After 40 hours for
PHA and 120 hours for other tests, $0.5 \mu \mathrm{Ci}$ tritiated thymidine in $0.05 \mathrm{ml}$ TC 199 was added to each well (TRK 61, Radio-chemicals Centre, Amersham; specific activity approx. $23 \mu \mathrm{Ci} / \mathrm{mmol}$ ). After an additional four hours for PHA or 18 hours for other tests the plates were harvested onto glass fibre filters using a multiple automated sample harvester(MASH, Dynatech Ltd.). Uptake of tritiated thymidine by the lymphocytes was assessed by liquid scintillation counting. Results are expressed as counts per minute increment (stimulated-unstimulated).

TRANSFER FACTOR

Healthy relatives of our patients were used as donors. All donors had a full clinical history and examination before being accepted. Anyone with past history of any serious disease was rejected, as were any with gastrointestinal symptoms or any with previous symptoms of sacroileitis or iritis.

All donors had normal full blood counts, sedimentation rate, chest radiograph, and VDRL and were negative for hepatitis B antigen. All had strongly positive tuberculin and SK/SD reactions as recommended by Lawrence et al. (1963).

Lymphocytes were harvested by leucopheresis from the donors. Transfer factor was prepared by the method of Lawrence and Al-Askari (1971). Briefly, the cells were disrupted by freezing and thawing, in the presence of deoxyribonuclease and dialysed into sterile pyrogen-free distilled water. The dialysate was lyophilised and then reconstituted with sterile saline so that each $1 \mathrm{ml}$ contained extract from $5 \times 10^{8}$ lymphocytes. Immediately before injection through a millipore filter, the extract was mixed with $0.5 \mathrm{ml} 1 \%$ lignocaine. Patients were given three injections intramuscularly into the deltoid muscle at monthly intervals. Patients receiving placebo were given $1.5 \mathrm{ml}$ normal saline similarly.

Neither the physician giving the injection nor the patient was aware of what was in the syringe. Transfer factor is a cloudy solution and therefore all syringes were covered in adhesive tape to prevent the physicians seeing the contents of the syringe.

\section{Results}

\section{CLINICAL}

Of the 33 patients who completed the trials there were 18 females and 15 males. Mean age for the transfer factor group was 33 years and mean age for the placebo group was 37 years.

A number of patients were receiving drugs at the start of the trial, but the dosage of none of the drugs was altered during the trial. Seven patients were taking salazopyrin. Five patients were taking 
Table 3 Comparison of two groups immediately before treatment (month 1)

\begin{tabular}{|c|c|c|c|c|c|c|c|c|}
\hline \multirow[t]{2}{*}{ Group } & \multirow[t]{2}{*}{ No. } & \multicolumn{2}{|c|}{ Age (yr) } & \multicolumn{2}{|c|}{ Number taking: } & \multicolumn{3}{|c|}{ Mean } \\
\hline & & Mean & Range & Salazopyrine & Prednisone & $H b$ & Albumin $(g / l)$ & $E S R$ \\
\hline $\begin{array}{l}\text { Transfer factor } \\
\text { Placebo }\end{array}$ & $\begin{array}{l}15 \\
18\end{array}$ & $\begin{array}{l}33 \\
37\end{array}$ & $\begin{array}{l}22-67 \\
21-69\end{array}$ & $\begin{array}{l}3 \\
4\end{array}$ & $\begin{array}{l}1 \\
4\end{array}$ & $\begin{array}{l}11 \cdot 8 \\
10.9\end{array}$ & $\begin{array}{l}36 \\
33\end{array}$ & $\begin{array}{l}27 \\
25\end{array}$ \\
\hline
\end{tabular}

prednisone but no patient was taking more than $12 \cdot 5$ mg. No patients were receiving azathioprine (Table 3).

There was no significant difference between mean $\mathrm{Hb}, \mathrm{ESR}$, and serum albumin between the two groups at the start of the trial, patients having been allocated to the two groups in order to produce two approximately comparable groups. The loss of four patients from the transfer factor group, however, caused slightly greater differences in the groups than was intended. There was no significant difference of $\mathrm{Hb}$, albumin, or ESR originally or at the end of the trial between the two groups (Table 4).

Table 4 Comparison of two groups after six months' treatment (month 9)

\begin{tabular}{llll}
\hline Group & Mean & & \\
\cline { 2 - 4 } & $H b$ & Albumin $(g / D)$ & ESR \\
\hline Transfer factor & $12 \cdot 1$ & 35 & 25 \\
Placebo & $11 \cdot 4$ & 34 & 28 \\
\hline
\end{tabular}

There was a significant difference $(\mathrm{P} 0.05)$ between the pooled results of CDAI for month 0 and 1 (Figs 1 and 2). There was no significant difference between the results of either group for months 1,4 , and 9 (Table 5). The four patients on whom surgery was

Table 5 Comparison of CDAI

\begin{tabular}{llrlr}
\hline Group & Month 0 & \multicolumn{1}{c}{ Month 1 } & Month 4 & Month 9 \\
\hline Transfer factor & $132 \pm 71$ & $96 \pm 45$ & $101 \pm 62$ & $72 \pm 46$ \\
Placebo & $162 \pm 85$ & $143 \pm 89$ & $132 \pm 83$ & $137 \pm 94$ \\
Pooled & $147 \pm 78$ & $109 \pm 67$ & $117 \pm 73$ & $105 \pm 70$ \\
\hline
\end{tabular}

performed have been removed from the calculations. The fact that all four were in the transfer factor group would, if they were included, weight the results against transfer factor, as they were obviously treatment failures.

\section{SKIN TESTS}

Of 33 patients completing the trial, 21 initially gave negative reactions to PPD and 20 negative reactions to SK/SD. Table 6 shows numbers converting their

Table 6 Numbers converting skin tests out of total number with negative tests

\begin{tabular}{llc}
\hline Tests & Transfer factor & Placebo \\
\hline PPD & $5 / 11$ & $1 / 10$ \\
SK/SD & $3 / 9$ & $2 / 11$ \\
\hline
\end{tabular}

skin tests and the total numbers with negative skin tests in each group.

Although numbers are small, it is apparent that some patients showed an increased skin reactivity to these antigens after transfer factor therapy.

\section{In vitro LYMPHOCYTE STUDIES}

There was no significant alteration in lymphocyte transformation using PHA, PPD, candida, or mixed lymphocyte reaction when comparing placebo and transfer factor groups at any stage during the investigations. Figures are shown in Table 7. Significance was calculated by Student's $t$ test. PPD results had a log-normal distribution and therefore no standard deviations are shown for this group.

There was no significant alteration of percentage T or B cells in either transfer factor or placebo group after treatment (Table 7). Again significance was calculated using Student's $t$ test.

\section{Discussion}

One of the difficulties in conducting trials in Crohn's disease has been finding a satisfactory method of assessing the activity of the disease. None of the systems used previously has been universally acceptable and consequently the assessment of treatments of Crohn's disease has been difficult. The Crohn's Disease Activity Index of Best et al. is the best of these systems of assessing disease activity, is gaining general acceptability, and has been used by the United States National Co-operative Crohn's Disease Group. All the parameters of this index were cross-checked for significance in being a true index of activity by Best and his colleagues.

The most striking finding that this trial has produced is the significant fall in CDAI produced in the 
Table 7 Lymphocyte function tests (figures in thousand counts/min increment $\pm S D$ )

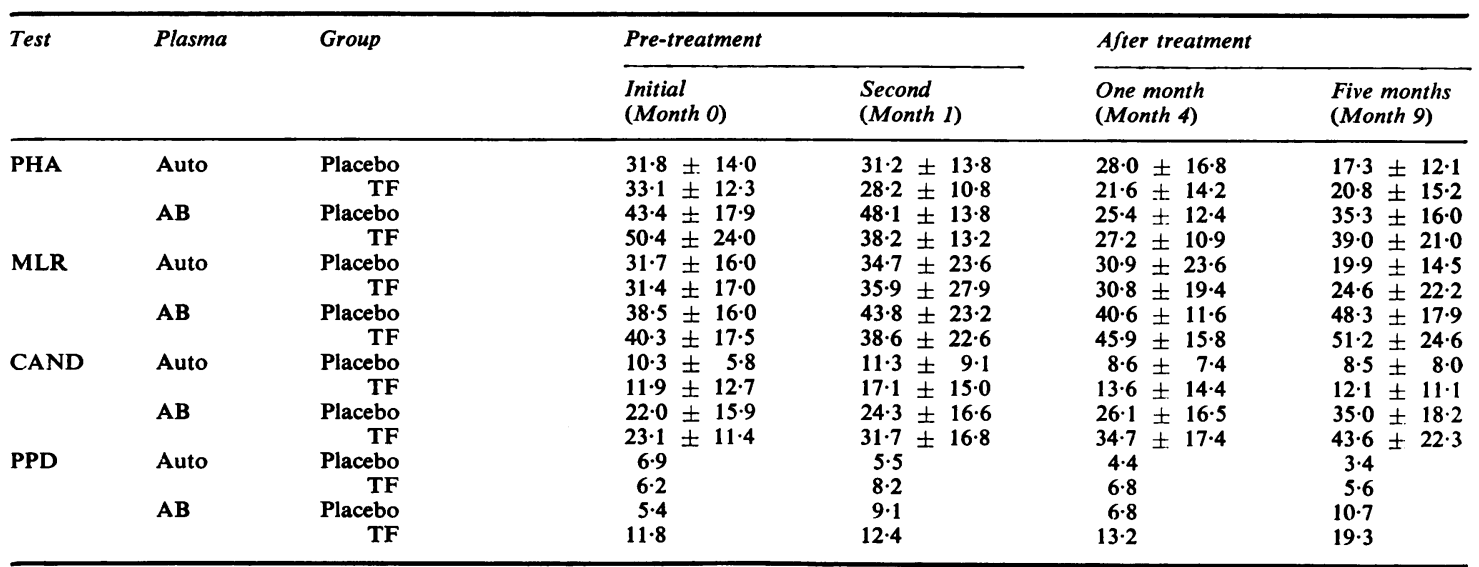

initial introducing period of one month. If the mean CDAI results at the first month had been compared with final mean CDAI a significant fall in activity would have been produced in the transfer factor group and thus a false result. For this reason it is suggested that an 'acclimatising' period of use of the CDAI should occur in trials using this index. The fall of CDAI score presumably represents a combination of factors. One of these is probably an initial introspection by patients caused by the need to assess their disease each day in order to fill in their diary cards satisfactorily. Possibly also there is a general increase in well-being induced by increased attention from the physicians.

The increased numbers of negative skin tests found in this study supports results found by some other workers (Meuwissen et al., 1975). That the transfer factor has some activity is shown by the conversion of some skin tests in the transfer factor group. It is interesting that the in vitro lymphocyte function is unchanged, and this has been found on occasions previously (Lawrence, 1970).

That transfer factor does not affect the course of Crohn's disease is probably an expected result in a disease where no definite antigen has been isolated, and no specific defect in $T$ cell function has been demonstrated. The results are in disagreement with the paper of Asquith et al. who presented seven patients treated with transfer factor, all of whom apparently showed some clinical improvement. Minor differences in preparation and giving of transfer factor are present between the two papers. Asquith et al. used subcutaneous injections with greater frequency than the intramuscular injections used in this study. The donors for transfer factor in this study were relatives of patients, whereas Asquith et al. used pooled donors. We deliberately used relatives or spouses of our patients who had been in recent prolonged contact with the patient. The specific agent or antigen causing Crohn's disease is not known but many authors believe that there are grounds for thinking it to be an infectious agent. Our hope was that our close relatives' lymphocytes had been sensitised with the unknown antigen and had developed a specific transfer factor to this antigen.

Finally, it is necessary to consider why transfer factor does not cause improvement in Crohn's disease. It is possible that our transfer factor was not specifically active because we used relatives of donors. It is also just possible that much larger, more frequent doses might produce better results. We believe that the most probable explanation, however, is that the abnormalities of $T$ cell function found by us ( $\mathrm{Ng}$ and Vicary, 1976) and others are an epiphenomenon, and therefore alerting Tcell function would not be expected to alter the course of the disease.

We wish to thank Dr S. Retsos for technical assistance.

\section{References}

Asquith, P., Kraft, S. C., and Rothberg, R. M. (1973). Lymphocyte responses to non-specific mitogens in inflammatory bowel disease. Gastroenterology, 65, 1-7.

Asquith, P., Mallas, E., Ross, I., Montgomery, R. D., Cooke, W. T., and Thompson, R. A. (1975). Transfer factor in the treatment of Crohn's disease (Abstract). Gut, $16,832$.

Best, W. R., Becktel, J. M., Singleton, J. W., and Kern, F. (1976). Development of a Crohn's Disease Activity Index. Gastroenterology, 70, 439-444.

Binder, H. J., Spiro, H. M., and Thayer, W. R. Jr. (1966). Delayed hypersensitivity in regional enteritis and ulcerative colitis. American Journal of of Digestive Diseases, 11, 572-574. 
Bird, A. G., and Britton, S. (1974). No evidence for decreased lymphocyte reactivity in Crohn's disease. Gastroenterology, 67, 926-932.

Bolton, P. M., James, S. L., Newcombe, R. G., Whitehead, R. H., and Hughes, L. E. (1974). The immune competence of patients with inflammatory bowel disease. Gut, 15 , 213-219.

Graybill, J. R., Silva, J. Jr., Alford, R. H., and Thor, D. E. (1973). Immunologic and clinical improvement of progressive coccidiomycosis following administration of transfer factor. Cellular Immunology, 8, 120-135.

Lawrence, H. S. (1955). The transfer in humans of delayed skin sensitivity to streptococcal $M$ substance and to tuberculin with disrupted leucocytes. Journal of Clinical Investigation, 34, 219-230.

Lawrence, H. S. (1970). Transfer factor and cellular immune deficiency. New England Journal of Medicine, 283, 411-419.

Lawrence, H. S., Al-Askari, S., David, J., Franklin, E. C., and Zweiman, B. (1963). Transfer of immunological information in humans with dialysates of leucocyte extracts. Transactions of the Association of American Physicians, 76, 84-91.

Lawrence, H. S. (1969). Transfer factor. Advances in Immunology, 11, 195-266.

Lawrence, H. S., and Al-Askari, A. (1971). The preparation and purification of transfer factor. In In Vitro Methods in
Cell Mediated Immunity, pp. 531-546. Edited by B. R. Bloom and P. R. Gade. Academic Press: New York.

Lennard-Jones, J. E., Ritchie, J. K., and Zohrab, W. J. (1976). Procotocolitis and Crohn's disease of the colon: a comparison of the clinical course. Gut, 17, 477-482.

Meuwissen, S. G. M., Schellekens, P. T. A., Huismans, L., and Tytgat, G. N. (1975). Impaired anamnestic cellular immune response in patients with Crohn's disease. Gut, $16,854-860$.

Meyers, S., Sachar, D. B., Taub, R. N., and Janowitz, H. D. (1976). Anergy to dinitrochlorobenzene and depression of T-lymphocytes in Crohn's disease and ulcerative colitis. Gut, 17, 911-915.

Ng, R. P., and Vicary, F. R. (1976). Cell mediated immunity and transfer factor in Crohn's disease. British Medical Journal, 2, 87-88.

O‘Connell, C. J., Karzon, D. T., Barron, A. L., Plaut, M. E., and Ali, V. M. (1964). Progressive vaccinia with normal antibodies: a case possibly due to deficient cellular immunity. Annals of Internal Medicine, 60, 282-289.

Pabst, H. F. and Swanson, R. (1972). Successful treatment of candidiasis with transfer factor. British Medical Journal, 2, 442-443.

Rocklin, R. E. (1975). Use of transfer factor in patients with depressed cellular immunity and chronic infection. Birth Defects: Original Article Series, 11, 431-435. 